\title{
Short-term variation in ambient concentrations and gas/particle partitioning of organochlorine pesticides in Izmir, Turkey
}

\author{
Aysun Sofuoglu ${ }^{\mathrm{a}, *}$, Eylem Cetin ${ }^{\mathrm{b}}$, Sevde Seza Bozacioglu ${ }^{\mathrm{a}}$, \\ Gaye Devrim Sener ${ }^{\mathrm{b}}$, Mustafa Odabasi ${ }^{\mathrm{b}}$ \\ a Department of Chemical Engineering, Faculty of Engineering, Izmir Institute of Technology, 35460 Gulbahce-Urla, Izmir, Turkey \\ ${ }^{\mathrm{b}}$ Department of Environmental Engineering, Faculty of Engineering, Dokuz Eylul University, Kaynaklar Campus, \\ 35160 Buca, Izmir, Turkey
}

Received 23 January 2004; accepted 20 May 2004

\begin{abstract}
Twenty successive daytime and nighttime air samples were collected and analyzed for 23 currently used and/banned organochlorine pesticides (OCPs) between 14 and 23 May 2003 in Izmir, Turkey. Average individual OCP concentrations ranged from $5 \pm 4 \mathrm{pg} \mathrm{m}^{-3}$ (p, $\mathrm{p}^{\prime}$-dichlorodiphenyldichloroethane) to $391 \pm 306 \mathrm{pg} \mathrm{m}^{-3}$ (chlorpyrifos) and they were within the ranges previously measured at different sites.

Most of the OCPs did not exhibit strong diurnal cycling. The temperature dependence of gas-phase atmospheric concentrations of OCPs investigated using Clausius-Clapeyron plots was statistically significant for $\beta$-HCH and endosulfan sulfate $(p<0.1)$ and was not significant for other compounds $(0-21 \%$ of the variability in their gas-phase concentrations). In addition to temperature, the effect of wind speed and direction was also investigated using multiple linear regression analysis and these three parameters together explained the $2 \%$ (aldrin) to $72 \%$ (endosulfan II) of the variability in gas-phase OCP concentrations. Results of the multiple regression analysis indicated that wind speed was a statistically significant factor for most of the OCPs and wind direction was important for some compounds. The temperature-dependent diurnal cycling of most OCPs was probably masked by the higher wind speeds observed during daytime periods with high temperatures, different source sectors and ongoing sources. The lack of correlation for heptachlor, aldrin, $\mathrm{p}, \mathrm{p}^{\prime}$-dichlorodiphenyldichloroethylene ( $\mathrm{p}-\mathrm{p}^{\prime}$-DDE), and $\mathrm{p}, \mathrm{p}^{\prime}$-dichlorodiphenyltrichloroethane $\left(\mathrm{p}-\mathrm{p}^{\prime}\right.$-DDT) with temperature, wind speed and direction suggested that their concentrations were affected by longrange transport.

The partitioning of OCPs between particle and gas phases was investigated and compared to $K_{\mathrm{OA}}$ (octanol/air partition coefficient) absorption model. The overall agreement between experimental and modeled $\log K_{\mathrm{p}}(\mathrm{gas} / \mathrm{particle}$ partition coefficient) values was good $(p<0.01$, slope $=0.94)$. Prediction of absorption model for particulate percentages was excellent for $\beta-\mathrm{HCH}$, endosulfan I, and p-p'-DDT. However, the model underpredicted the particulate percentages for $\alpha, \gamma$-HCHs, chlorpyrifos, and dieldrin, and overpredicted those for $\mathrm{p}-\mathrm{p}^{\prime}$-DDE.
\end{abstract}

(C) 2004 Elsevier Ltd. All rights reserved.

Keywords: Organochlorine pesticides (OCPs); Gas/particle partitioning; Temperature dependence

\footnotetext{
*Corresponding author. Tel.: +90-232-750-6283; fax: +90-232-750-6196.

E-mail address: aysunsofuoglu@iyte.edu.tr (A. Sofuoglu).
} 


\section{Introduction}

Organochlorine pesticides (OCPs) are a broad class of semivolatile organic compounds (SOCs) that were widely used as insecticides in the past. The atmosphere is a major pathway for the transport, deposition, degradation, and cycling of past and present SOCs. Past SOCs are defined as those that have been banned/restricted. They do not have any point sources around a sampling site. However, present SOCs have ongoing uses and point/diffuse sources around a sampling site (Lee et al., 2000).

It has been shown that the ambient concentrations of SOCs are affected by seasonal temperature variations and long-range transport (Sofuoglu et al., 2001; Lee and Jones, 1999; Cortes et al., 1998; Hoff et al., 1998; Honrath et al., 1997; Hillery et al., 1997; Wania et al., 1998). As the temperature rises, gas-phase air concentrations increase as a result of volatilization from previously contaminated surfaces such as soil, atmospheric particles, water, and vegetation. Short-term studies have indicated that ambient gas-phase SOCs also respond to short-term temperature changes resulting in rapid movement between environmental compartments (i.e., diurnal cycling) (Lee et al., 1998, 2000). Advection and ongoing sources are other important factors affecting the variation of ambient gas-phase OCP concentrations.

Izmir Metropolitan City is the center of a highly industrialized area by the Aegean Sea shoreline of Turkey. Izmir is located in a basin surrounded by mountain series of $\sim 1000-1500 \mathrm{~m}$ height with only the west end open to the Aegean Sea. The climate is Mediterranean with warm and rainy winters, hot and dry summers. The major air movements over the area are mainly from northerly directions. The city with 2.7 million population has sizeable economic, industrial, and agricultural activities emitting high quantities of air pollutants. The use of most of the OCPs was banned/ restricted in Turkey as in many countries due to persistent contamination of the environment. However, some OCPs (chlorpyrifos and endosulfan) are currently used. The average annual use of chlorpyrifos and endosulfan in Izmir area between 1998 and 2002 was estimated as 890 and $6700 \mathrm{~kg}$, respectively (Ministry of Agriculture, 2003).

OCP levels have been widely measured around the world. However, very little information exists on their environmental levels in different compartments (surface waters, sediment, and biota) in Turkey (Turgut, 2003; Ayas et al., 1997) and there are no previous studies on atmospheric OCP concentrations.

The objectives of this study were to: (1) measure OCP concentrations and their short-term variation, (2) investigate their relationship with temperature and wind speed and direction, and (3) investigate their gas/particle partitioning.

\section{Experimental}

\subsection{Sample collection}

Twenty ambient air samples were collected between 14 and 23 May 2003 on a $4 \mathrm{~m}$ high sampling platform located on the Kaynaklar campus of the Dokuz Eylul University, Izmir, Turkey. The sampling site is located $\sim 10 \mathrm{~km}$ southeast of Izmir's center. The campus is relatively far from any settlement zones or industrial facilities. There are residential areas located $\sim 2 \mathrm{~km}$ southwest and a highway $0.5 \mathrm{~km}$ south of the sampling site. Land cover in the immediate area is a young coniferous forest. There are steel plants, a petroleum refinery, and a petrochemical industry located $45 \mathrm{~km}$ to the northwest. The nearest industrial facility is a cement work about $10 \mathrm{~km}$ at the north and an open road gravel storage site nearly $3 \mathrm{~km}$ at the east. Samples were collected during successive daytime ( 8.00 a.m. -8.00 p.m.) and nighttime ( 8.00 p.m. -8.00 a.m.) periods. Meteorological data were obtained from a $10 \mathrm{~m}$ high tower located at the same site (Table 1).

Air samples were collected using a modified highvolume sampler, Model GPS-11 (Thermo-Andersen Inc.). Particles were collected on $10.5-\mathrm{cm}$ diameter quartz filters. The gas-phase compounds were collected in a modified cartridge containing XAD-2 resin placed between layers of polyurethane foam (PUF). Concurrently, particulate samples were collected on $11-\mathrm{cm}$ diameter glass fiber filters using another high volume sampler to determine total suspended particulate (TSP) matter and its organic matter (OM) content. Average sampling time was $12 \mathrm{~h}$. The average sampling volumes were $223 \pm 8$ and $41 \pm 4 \mathrm{~m}^{3}$ for pesticide and TSP samples, respectively.

\subsection{Sample preparation and analysis}

Prior to sampling, quartz filters were wrapped loosely with aluminum foil and they were baked overnight at $450^{\circ} \mathrm{C}$ in a muffle furnace to remove any organic residues. They were then allowed to cool to room temperature in a desiccator. PUF cartridges were cleaned by Soxhlet extraction using 1:1 acetone:hexane mixture for $12 \mathrm{~h}$. After extraction the cartridges and resin were wrapped loosely with aluminum foil and dried in an oven at $70^{\circ} \mathrm{C}$. Cleaned cartridges were stored in glass jars capped with Teflon-lined lids.

Collected samples were Soxhlet extracted with a mixture of dichloromethane (DCM): petroleum ether (PE) (20:80) for $12 \mathrm{~h}$. All sample extracts were concentrated and transferred into hexane using a rotary evaporator and a high purity stream of nitrogen. After volume reduction to $2 \mathrm{ml}$ and transfer into hexane, samples were cleaned up on an alumina-silicic acid column containing $3 \mathrm{~g}$ silicic acid ( $3 \%$ water) and $2 \mathrm{~g}$ 
Table 1

Summary of meteorological, TSP, and OM data

\begin{tabular}{|c|c|c|c|c|c|c|c|c|}
\hline $\begin{array}{l}\text { Sample } \\
\text { number }\end{array}$ & Date & $\begin{array}{l}\text { Wind } \\
\text { direction }\end{array}$ & $\begin{array}{l}\text { Relative } \\
\text { humidity (\%) }\end{array}$ & $\begin{array}{l}\text { Wind speed } \\
\left(\mathrm{m} \mathrm{s}^{-1}\right)\end{array}$ & $\begin{array}{l}\text { Temperature } \\
\left({ }^{\circ} \mathrm{C}\right)\end{array}$ & $\begin{array}{l}\text { TSP } \\
\left(\mu \mathrm{g} \mathrm{m}^{-3}\right)\end{array}$ & $\begin{array}{l}\mathrm{OM} \\
\left(\mu \mathrm{g} \mathrm{m}^{-3}\right)\end{array}$ & $\begin{array}{l}\mathrm{OM} \\
(\%)\end{array}$ \\
\hline 1 & 05.14 .2003 & WNW & 53 & 2.8 & 23.5 & 72 & 59 & 81 \\
\hline 2 & 05.14 .2003 & ESE & 69 & 1.4 & 18.2 & 73 & 45 & 62 \\
\hline 3 & 05.15 .2003 & WNW & 47 & 2.2 & 25.0 & 84 & 44 & 52 \\
\hline 4 & 05.15 .2003 & $\mathrm{~N}$ & 64 & 0.8 & 20.1 & 101 & 52 & 51 \\
\hline 5 & 05.16 .2003 & WNW & 43 & 3.4 & 26.4 & 127 & 54 & 43 \\
\hline 6 & 05.16 .2003 & $\mathrm{~N}$ & 63 & 0.9 & 20.8 & 95 & 39 & 41 \\
\hline 7 & 05.17 .2003 & WNW & 45 & 3.5 & 25.7 & 95 & 59 & 62 \\
\hline 8 & 05.17 .2003 & $\mathrm{~N}$ & 68 & 1.2 & 20.0 & 89 & 18 & 20 \\
\hline 9 & 05.18 .2003 & WNW & 58 & 5.0 & 23.2 & 109 & 57 & 52 \\
\hline 10 & 05.18 .2003 & NW & 79 & 1.7 & 18.0 & 90 & 35 & 39 \\
\hline 11 & 05.19 .2003 & NW & 64 & 5.1 & 21.9 & 108 & 59 & 55 \\
\hline 12 & 05.19 .2003 & WNW & 74 & 4.3 & 17.2 & 77 & 37 & 48 \\
\hline 13 & 05.20 .2003 & $\mathrm{~N}$ & 56 & 5.5 & 22.5 & 107 & 47 & 44 \\
\hline 14 & 05.20 .2003 & NW & 72 & 1.0 & 18.5 & 125 & 87 & 69 \\
\hline 15 & 05.21 .2003 & ESE & 53 & 3.1 & 24.2 & 93 & 55 & 59 \\
\hline 16 & 05.21 .2003 & WNW & 72 & 2.4 & 16.9 & 48 & 27 & 57 \\
\hline 17 & 05.22 .2003 & ESE & 51 & 6.0 & 22.6 & 73 & 34 & 47 \\
\hline 18 & 05.22 .2003 & SSE & 72 & 3.8 & 17.3 & 25 & 14 & 55 \\
\hline 19 & 05.23 .2003 & SE & 50 & 3.8 & 21.5 & 43 & 25 & 58 \\
\hline 20 & 05.23 .2003 & SE & 83 & 2.2 & 15.7 & 33 & 24 & 73 \\
\hline Average & & & 62 & 3 & 21 & 83 & 44 & 53 \\
\hline $\mathrm{SD}$ & & & 12 & 2 & 3 & 29 & 18 & 13 \\
\hline
\end{tabular}

alumina (6\% water) (Odabasi et al., 1999; Sofuoglu et al., 2001). The column was prewashed with $20 \mathrm{ml}$ DCM followed by $20 \mathrm{ml}$ PE. The sample in $2 \mathrm{ml}$ hexane was added to the top of column, heptachlor, aldrin, p, $\mathrm{p}^{\prime}$-dichlorodiphenyldichloroethylene (p-p'DDE), polychlorinated naphthalenes, and polychlorinated biphenyls (PCBs) were eluted with $25 \mathrm{ml} \mathrm{PE}$ (fraction 1). Polycyclic aromatic hydrocarbons (PAHs) and the other 20 OCPs were eluted with $20 \mathrm{ml} \mathrm{DCM}$ (fraction 2). For both fractions the solvent was exchanged into hexane, and the final sample volume was adjusted to $1 \mathrm{ml}$ by nitrogen blow-down. Decachloro biphenyl (PCB 209) was used as the internal standard for fraction 2. Before analysis, samples were spiked with 25 ng PCB 209.

Samples were analyzed for OCPs with an Agilent $6890 \mathrm{~N}$ gas chromatograph (GC) equipped with a microelectron capture detector ( $\mu$-ECD). A capillary column (DB5-ms, $30 \mathrm{~m}, 0.25 \mathrm{~mm}, 0.25 \mu \mathrm{m}$ ) was used. The initial oven temperature was held at $50^{\circ} \mathrm{C}$ for $1 \mathrm{~min}$ and raised to $100^{\circ} \mathrm{C}$ at $25^{\circ} \mathrm{C} \mathrm{min}^{-1}, 100-300^{\circ} \mathrm{C}$ at $5^{\circ} \mathrm{C} \mathrm{min}^{-1}$, and held for $7 \mathrm{~min}$. The injector and detector temperatures were $250^{\circ} \mathrm{C}$ and $320^{\circ} \mathrm{C}$, respectively. High-purity helium and nitrogen were used as carrier and detector make-up gases, respectively. Fractions 1 and 2 were run separately. OCPs in fraction 2 were quantified using the internal calibration procedure. Since fraction 1 also contained the PCBs, PCB-209 could not be used as the internal standard for this fraction. Therefore, OCPs (heptachlor, aldrin, p-p'-DDE) in fraction 1 were quantified using the external calibration procedure. $\alpha$ Chlordane and endosulfan I were coeluted from the chromatographic column used. Therefore, they were reported as $\alpha$-chlordane + endosulfan I.

Prior to sampling for TSP, glass fiber filters were wrapped loosely with aluminum foil and they were baked overnight at $450^{\circ} \mathrm{C}$ in a muffle furnace to remove any organic residues. They were then allowed to cool to room temperature in a desiccator and were weighed using a micro-balance capable of weighing $0.1 \mathrm{mg}$. After sample collection filters were kept in a desiccator overnight and they were reweighed. TSP was determined by subtracting the initial weight from the final weight. To determine the OM content of the particles, filters were then baked for $1 \mathrm{~h}$ at $450^{\circ} \mathrm{C}$ in a furnace, allowed to cool to room temperature in a desiccator, and weighed. OM was determined by subtracting the final weight (after baking) from the initial weight (before baking). It is possible that the determination of OM content by this method may be interfered by the weight loss of glass fiber filters at high temperatures. The hourly weight loss of filters at $450^{\circ} \mathrm{C}$ with time was monitored for $12 \mathrm{~h}$. It was observed that the maximum weight loss $(3 \mathrm{mg})$ occurs within a $2 \mathrm{~h}$ period and the weight loss 
decreases to $0.3 \mathrm{mgh}^{-1}$ and becomes stable for the remaining period. Since this experiment did not indicate when the weight loss stops, concurrent blank filters were run for each sample to minimize the interference from weight loss of filters at high temperatures in OM determination. Determined OM contents were corrected using the weight loss in blank filters during baking. The average weight loss of blank filters $(0.3 \mathrm{mg})$ was significantly lower than the average weight loss of the samples $(2.2 \mathrm{mg})$ indicating that the interference was not significant in OM determination.

\subsection{Quality control}

Procedural recoveries of OCPs were determined externally $(n=6)$ and they ranged from $40 \pm 11 \%$ (endosulfan II) to $128 \pm 22 \%$ (endosulfan sulfate). Eighteen of the individual OCPs had recoveries $>70 \%$ (Table 2). Since the recoveries were generally high, sample amounts were not corrected for procedural recoveries.
Instrumental detection limits (IDLs) were determined from sequential injections of diluted standard solutions of the analyzed compounds. The quantifiable amounts of OCPs ranged from $9(\alpha, \beta, \gamma-\mathrm{HCHs}$, aldrin, $t$-nonachlor, p-p'-DDE) to $75 \mathrm{fg}$ (chlorpyrifos, heptachlor epoxide, $c$-nonachlor) for $1 \mu \mathrm{l}$ injection volume (Table 2). Blank PUF cartridges and filters were routinely placed in the field to determine if there was any contamination during sample handling and preparation. For the compounds detected in blanks the limit of detection (LOD, ng) of the method was defined as the mean blank mass plus three standard deviations. IDLs were used for the compounds that were not detected in blanks. LODs for OCPs ranged from $9 \mathrm{pg}$ $(\alpha, \gamma$-HCHs, $t$-nonachlor) to $12.6 \mathrm{ng}$ (endosulfan sulfate) for PUFs and from $9 \mathrm{pg}$ ( $t$-nonachlor) to $12.9 \mathrm{ng}$ (endosulfan sulfate) for filters (Table 2). In general, OCP amounts in the samples were substantially higher than LODs. Sample quantities exceeding the LOD were quantified and blank-corrected by subtracting the mean blank amount from the sample amount.

Table 2

Procedural recoveries (average $\pm \mathrm{SD}$ ), blank amounts, instrumental detection limits (IDL), and limits of detection for the method (LOD)

\begin{tabular}{|c|c|c|c|c|c|c|c|}
\hline \multirow[t]{2}{*}{ Pesticide } & \multicolumn{2}{|c|}{ Recovery (\%) } & \multicolumn{2}{|c|}{ Blank amounts (ng) } & \multirow[t]{2}{*}{ IDL (ng) } & \multicolumn{2}{|c|}{ LOD (ng) } \\
\hline & PUF & Filter & PUF & Filter & & PUF & Filter \\
\hline$\alpha-\mathrm{HCH}$ & $91 \pm 4$ & 885 & nd & 0.3 & 0.009 & 0.009 & 0.450 \\
\hline$\beta$-HCH & $102 \pm 10$ & $95 \pm 3$ & 6.7 & 2.9 & 0.009 & 9.6 & 3.0 \\
\hline$\gamma-\mathrm{HCH}$ & $94 \pm 4$ & $92 \pm 7$ & nd & 0.6 & 0.009 & 0.009 & 0.820 \\
\hline$\delta$-HCH & $106 \pm 11$ & $104 \pm 15$ & nd & nd & 0.038 & 0.038 & 0.038 \\
\hline HEPCHL & $74 \pm 7$ & $74 \pm 6$ & 1.8 & 1.5 & 0.038 & 2.1 & 1.8 \\
\hline CHLPYR & $98 \pm 17$ & $98 \pm 6$ & 3.7 & 2.8 & 0.075 & 6.9 & 3.1 \\
\hline ALD & $77 \pm 8$ & $77 \pm 7$ & 3.0 & 2.6 & 0.009 & 3.9 & 2.8 \\
\hline HEP EPOX & $91 \pm 13$ & $87 \pm 6$ & 2.4 & nd & 0.075 & 5.6 & 0.075 \\
\hline$\gamma-\mathrm{CHL}$ & $87 \pm 8$ & $84 \pm 4$ & nd & nd & 0.019 & 0.019 & 0.019 \\
\hline$\alpha-\mathrm{CHL}+\mathrm{ESLF}$ I & $64 \pm 1$ & $74 \pm 6$ & 0.6 & 1.0 & 0.028 & 4.0 & 1.6 \\
\hline$t$-NONA & $69 \pm 8$ & $62 \pm 10$ & nd & nd & 0.009 & 0.009 & 0.009 \\
\hline p-p'-DDE & $80 \pm 8$ & $81 \pm 6$ & 1.0 & 0.7 & 0.009 & 1.3 & 1.1 \\
\hline DIELD & $87 \pm 15$ & $84 \pm 9$ & 0.4 & nd & 0.019 & 2.3 & 0.019 \\
\hline END & $89 \pm 17$ & $79 \pm 14$ & nd & 0.2 & 0.019 & 0.019 & 1.2 \\
\hline ESLF II & $40 \pm 11$ & $42 \pm 4$ & nd & nd & 0.019 & 0.019 & 0.019 \\
\hline p-p'-DDD & $85 \pm 12$ & $84 \pm 6$ & nd & nd & 0.019 & 0.019 & 0.019 \\
\hline END AL & $54 \pm 19$ & $62 \pm 15$ & nd & nd & 0.038 & 0.038 & 0.038 \\
\hline$c$-NONA & $68 \pm 16$ & $80 \pm 5$ & nd & nd & 0.075 & 0.075 & 0.075 \\
\hline ESLF SUL & $126 \pm 22$ & $128 \pm 22$ & 2.0 & 6.6 & 0.038 & 12.6 & 12.9 \\
\hline p-p'-DDT & $86 \pm 5$ & $76 \pm 10$ & nd & nd & 0.019 & 0.019 & 0.019 \\
\hline END KET & $122 \pm 24$ & $122 \pm 24$ & nd & nd & 0.019 & 0.019 & 0.019 \\
\hline MEOCL & $117 \pm 17$ & $110 \pm 8$ & nd & nd & 0.075 & 0.075 & 0.075 \\
\hline
\end{tabular}

nd: not detected.

$\alpha, \beta, \gamma, \delta$-Hexachlorocyclohexane isomers $(\alpha, \beta, \gamma, \delta$-HCH), heptachlor (HEPCHL), chlorpyrifos (CHLPYR), aldrin (ALD), heptachlor epoxide (HEP EPOX), $\gamma$-chlordane $\left(\gamma\right.$-CHL), $\alpha$-chlordane $\left(\alpha\right.$-CHL), endosulfan I (ESLF I), trans-nonachlor $\left(t\right.$-NONA), p, p $^{\prime}-$ dichlorodiphenyldichloroethylene (p-p'-DDE), dieldrin (DIELD), endrin (END), endosulfan II (ESLF II), p, p'-dichlorodiphenyldichloroethane (p-p'-DDD), endrin aldehyde (END AL), cis-nonachlor ( $c$-NONA), endosulfan sulfate (ESLF SUL), p,p'dichlorodiphenyltrichloroethane (p-p'-DDT), endrin ketone (END KET), methoxychlor (MEOCL). 
OCP standards were obtained from Accustandard (New Haven, CT, USA). The calibration standard solution contained 23 OCPs and PCB 209 as the internal standard. Five levels of calibration standards (1.2, 12, 40, 80, and $120 \mathrm{ng} \mathrm{ml}^{-1}$ for 21 OCPs, 2.4, 24, 160, $240 \mathrm{ng} \mathrm{ml}^{-1}$ for endosulfan I and II, and PCB 209 at a fixed concentration of $25 \mathrm{ng} \mathrm{ml}^{-1}$ ) were used to prepare the calibration curves. For all compounds the linear fit was good $\left(r^{2}>0.99\right)$.

ChemStation software was used for the identification of OCPs in the samples. Identification of individual OCPs was based on their retention times (within $\pm 0.05 \mathrm{~min}$ of the retention time of calibration standard).

A midrange calibration standard was analyzed for every 12 -h period to confirm GC-ECD performance (i.e., peak area, retention time). Samples were analyzed occasionally as duplicates. Differences in duplicate samples were $<5 \%$.

Sampling artifacts associated with the glass fiber filters and PUF may influence the apparent gas-particle distributions of OCPs. Gas-phase OCPs may adsorb to the filter and particles collected on the filter or relatively more volatile compounds may be desorbed from the collected particles by continuing gas flow if the gasphase concentration decreases or if the temperature increases during the sampling period. The extent of adsorption of gas-phase compounds is often estimated using a backup filter. Backup filters were not used in this study. However, a recent study indicated that the percent mass on the second filter was not significant (below 10\%) for OCPs (Yeo et al., 2003). In the present study, since the sampling was conducted during relatively short periods ( $12 \mathrm{~h}$, day or nighttime) the temperature fluctuations were also minimized. Therefore, it was assumed that sampling artifacts and their effect on the experimentally determined gas-particle distributions were not significant.

\section{Results and discussion}

\subsection{Ambient organochlorine pesticide concentrations}

Average individual OCP concentrations ranged from $5 \pm 4 \mathrm{pg} \mathrm{m}^{-3} \quad$ (p, $\mathrm{p}^{\prime}$-dichlorodiphenyldichloroethane) to $391 \pm 306 \mathrm{pg} \mathrm{m}^{-3}$ (chlorpyrifos) (average \pm SD) (Table 3). These concentrations were within the ranges previously measured at different sites. $c$-Nonachlor was not detected in any of the samples. Chlorpyrifos, a currently used pesticide had the highest average concentration and was followed by endosulfan sulfate (a degradation product of another currently used pesticide, endosulfan), $\beta$ - $\mathrm{HCH}$, methoxychlor, and $\alpha-\mathrm{CHL}+$ endosulfan I (Table 3). $\alpha-\mathrm{HCH}$ and $\gamma-\mathrm{HCH}$ concentrations were similar to those measured at other sites. However, average $\beta$ - $\mathrm{HCH}$ concentration observed in this study was higher than the ones reported for different sites. The average ratio of $\alpha-\mathrm{HCH}$ to $\gamma-\mathrm{HCH}$ was $1.2 \pm 0.5$. It was reported that $\alpha-\mathrm{HCH} / \gamma-\mathrm{HCH}$ ratios were close to 1 in areas where lindane $(\gamma-\mathrm{HCH})$ was used, and between 3 and 7 in areas where technical $\mathrm{HCH}$ was used or in remote areas (Lee et al., 2000; Murayama et al., 2003). $\alpha-\mathrm{HCH} / \gamma-\mathrm{HCH}$ ratios $>6$ were reported for Arctic atmosphere (Halsall et al., 1998). The use of technical $\mathrm{HCH}$ and lindane has been prohibited for more than 20 years in Turkey. However, lindane is currently used in Europe (Lee et al., 2000). A recent study conducted using passive samplers at a continental scale reported that $\alpha-\mathrm{HCH} / \gamma-\mathrm{HCH}$ ratios were generally $<1$ in neighboring countries (Greece and Cyprus) and over the Europe (Jaward et al., 2004). Therefore, the relatively low $\alpha-\mathrm{HCH} / \gamma-\mathrm{HCH}$ ratios observed in this study can be attributed to the effect of regional sources.

Even though endosulfan has been used in greater quantities during recent years in the area (usage of endosulfans/chlorpyrifos $=7.5$ ), chlorpyrifos concentrations were higher than endosulfan concentrations (ambient endosulfans/chlorpyrifos $=0.9 \pm 1.0$ ). When endosulfan sulfate is included, ambient endosulfans/ chlorpyrifos ratio becomes $2.3 \pm 1.9$. However, this ratio is substantially lower than the ratio of 7.5 that was estimated for their usage. The relatively lower endosulfan concentrations observed may be due to different properties (i.e., vapor pressure, air/water partition coefficient, octanol/air partition coefficient, and reactivity in the atmosphere) of endosulfans and chlorpyrifos and as a result, their different transport, transformation and removal in the environment.

Fig. 1 shows the correlations between related OCPs. $\mathrm{HCH}$ isomers, endosulfan I, II and endosulfan sulfate, chlordane related compounds (heptachlor, heptachlor epoxide, and $t$-nonachlor) were correlated, indicating that their concentrations were affected by similar factors (local ongoing or regional sources, meteorological parameters). However, DDT and its degradation products DDE and DDD were not correlated probably due to their distant sources.

\subsection{Effect of meteorological parameters on gas-phase OCP concentrations}

It has been shown that the gas-phase air concentrations of SOCs have a strong relationship to ambient temperature (Lee and Jones, 1999; Cortes et al., 1998; Hoff et al., 1998; Honrath et al., 1997). As the temperature rises, gas-phase air concentrations increase as a result of volatilization from surfaces such as soil, atmospheric particles, water, and vegetation. The temperature dependence of gas-phase ambient concentrations of SOCs has been investigated using ClausiusClapeyron plots (Lee and Jones, 1999; Cortes et al., 1998; Hoff et al., 1998; Honrath et al., 1997; Hillery 
Table 3

Concentrations of OCPs $\left(\mathrm{pg} \mathrm{m}^{-3}\right)$ in Izmir, Turkey and other sites

\begin{tabular}{|c|c|c|c|c|c|c|c|c|}
\hline & \multicolumn{3}{|c|}{ Izmir, Turkey $^{\mathrm{a}}$} & \multirow{2}{*}{$\begin{array}{l}\text { Galveston } \\
\text { Bay, TX }\end{array}$} & \multirow{2}{*}{$\begin{array}{l}\text { Niigata, } \\
\text { Japan }^{c}\end{array}$} & \multirow{2}{*}{$\begin{array}{l}\text { Hong } \\
\text { Kong }^{\mathrm{d}}\end{array}$} & \multirow{2}{*}{$\begin{array}{l}\text { Chicago, } \\
\text { IL }^{\mathrm{e}}\end{array}$} & \multirow{2}{*}{$\begin{array}{l}\text { Alert, Canadian } \\
\text { Arctic }^{\mathrm{f}}\end{array}$} \\
\hline & Range & Average $\pm \mathrm{SD}$ & $n$ & & & & & \\
\hline$\alpha-\mathrm{HCH}$ & $4-462$ & $111 \pm 125$ & 20 & 79 & 92 & 119 & 110 & 60 \\
\hline$\beta$-HCH & $63-631$ & $320 \pm 176$ & 20 & 4 & 23 & 41 & & 0.8 \\
\hline$\gamma-\mathrm{HCH}$ & $1-666$ & $117 \pm 157$ & 20 & 135 & 32 & 36 & 150 & 10 \\
\hline$\delta$-HCH & $24-53$ & $38 \pm 15$ & 3 & 47 & 3 & & & \\
\hline HEPCHL & $2-24$ & $7 \pm 6$ & 19 & 30 & & 65 & & 0.1 \\
\hline CHLPYR & $38-1068$ & $391 \pm 306$ & 20 & & & & & \\
\hline ALD & $3-11$ & $6 \pm 3$ & 14 & 6 & & & & \\
\hline HEP EPOX & $8-110$ & $34 \pm 35$ & 14 & 13 & & & & 1 \\
\hline$\gamma-\mathrm{CHL}$ & $13-894$ & $158 \pm 262$ & 15 & 38 & 64 & & 130 & 0.5 \\
\hline$\alpha-\mathrm{CHL}+\mathrm{ESLF}$ I & $96-342$ & $171 \pm 60$ & 19 & $30^{\mathrm{g}}$ & $78^{\mathrm{g}}$ & $57^{\mathrm{h}}$ & $120^{\mathrm{g}}$ & $4^{\mathrm{h}}$ \\
\hline$t$-NONA & $2-387$ & $50 \pm 126$ & 9 & 26 & & & 80 & 0.9 \\
\hline $\mathrm{p}-\mathrm{p}^{\prime}-\mathrm{DDE}$ & $8-35$ & $20 \pm 8$ & 20 & 11 & 5 & 20 & & 0.4 \\
\hline DIELD & $3-114$ & $35 \pm 39$ & 7 & 19 & & & & 1 \\
\hline END & $5-25$ & $16 \pm 10$ & 3 & 1 & & & & 0.2 \\
\hline ESLF II & $3-30$ & $20 \pm 7$ & 13 & & & & & \\
\hline p-p'-DDD & $0.5-11$ & $5 \pm \overline{4}$ & 6 & 2 & $<2$ & & 100 & \\
\hline END AL & 19-149 & $48 \pm 38$ & 17 & & & & & \\
\hline$c$-NONA & nd & nd & 0 & 4 & & & & 0.1 \\
\hline ESLF SUL & $46-1271$ & $369 \pm 375$ & 16 & & & & & \\
\hline p-p'-DDT & $5-75$ & $29 \pm 21$ & 18 & 8 & 6 & 26 & 70 & 0.1 \\
\hline END KET & $6-82$ & $41 \pm 26$ & 8 & & & & & \\
\hline MEOCL & $43-990$ & $220 \pm 255$ & 20 & & & & & 0.3 \\
\hline
\end{tabular}

Note: $n$, number of the samples above the detection limit; nd, not detected.

${ }^{a}$ This study (particle + gas phase).

${ }^{\mathrm{b}}$ Park et al. (2001) (gas phase).

${ }^{\mathrm{c}}$ Murayama et al. (2003) (particle + gas phase).

${ }^{\mathrm{d}}$ Louie and $\operatorname{Sin}$ (2003) (particle + gas phase).

${ }^{\mathrm{e}}$ Sofuoglu et al. (2001) (gas phase).

${ }^{\mathrm{f}}$ Halsall et al. (1998) (particle + gas phase).

$\mathrm{g}$ a-Chlordane.

${ }^{\mathrm{h}}$ Endosulfan.

et al., 1997) and surface exchange models (Wania et al., 1998).

Studies by Lee et al. $(2000,1998)$ have reported that OCPs and other SOCs followed clear diurnal cycles for the first 5 days of their study when the stable atmospheric conditions were dominant. However, for the last 2 days as a more unstable and cooler weather started to influence the sampling site, OCP concentrations were controlled primarily by advection (Lee et al., 2000). Most of the OCPs did not exhibit strong diurnal cycling in the present study. Diurnal variation $\beta-\mathrm{HCH}$ was illustrated as an example in Fig. 2, which was apparent only for the period between samples 10 and 16 .

The variation in atmospheric SOC concentrations can be quantified using the Clausius-Clapeyron equation

$\ln P=\left(-\Delta H_{\mathrm{v}} / R\right)(1 / T)+$ constant,

where $P$ is the gas-phase SOC partial pressure (atm), $\Delta H_{\mathrm{v}}$ is the enthalpy of vaporization $\left(\mathrm{kJ} \mathrm{mol}^{-1}\right), R$ is the gas constant, and $T$ is the average atmospheric temperature $(\mathrm{K})$ during the sampling period. $\Delta H_{\mathrm{v}}$ is the heat required for phase change of a pure compound. In real environments, Simcik et al. (1999) suggested that $\Delta H_{\mathrm{v}}$ could be defined as the energy necessary to cause the phase transition from the surface of soil, water, or vegetation to the atmosphere.

The temperature dependence of gas-phase atmospheric concentrations of OCPs in this study was investigated using plots of $\ln P$ vs. $1 / T$ (Eq. (1)). The regression of $\ln P$ against $1 / T$ should be linear with a negative slope $m$ and an intercept $b$ (Currado and Harrad, 2000; Simcik et al., 1999):

$\ln P=m(1 / T)+b$.

Partial pressures (atm) of individual compounds were calculated for each sample using gas-phase concentrations and the ideal gas law. Natural logarithms of calculated partial pressures were plotted against 

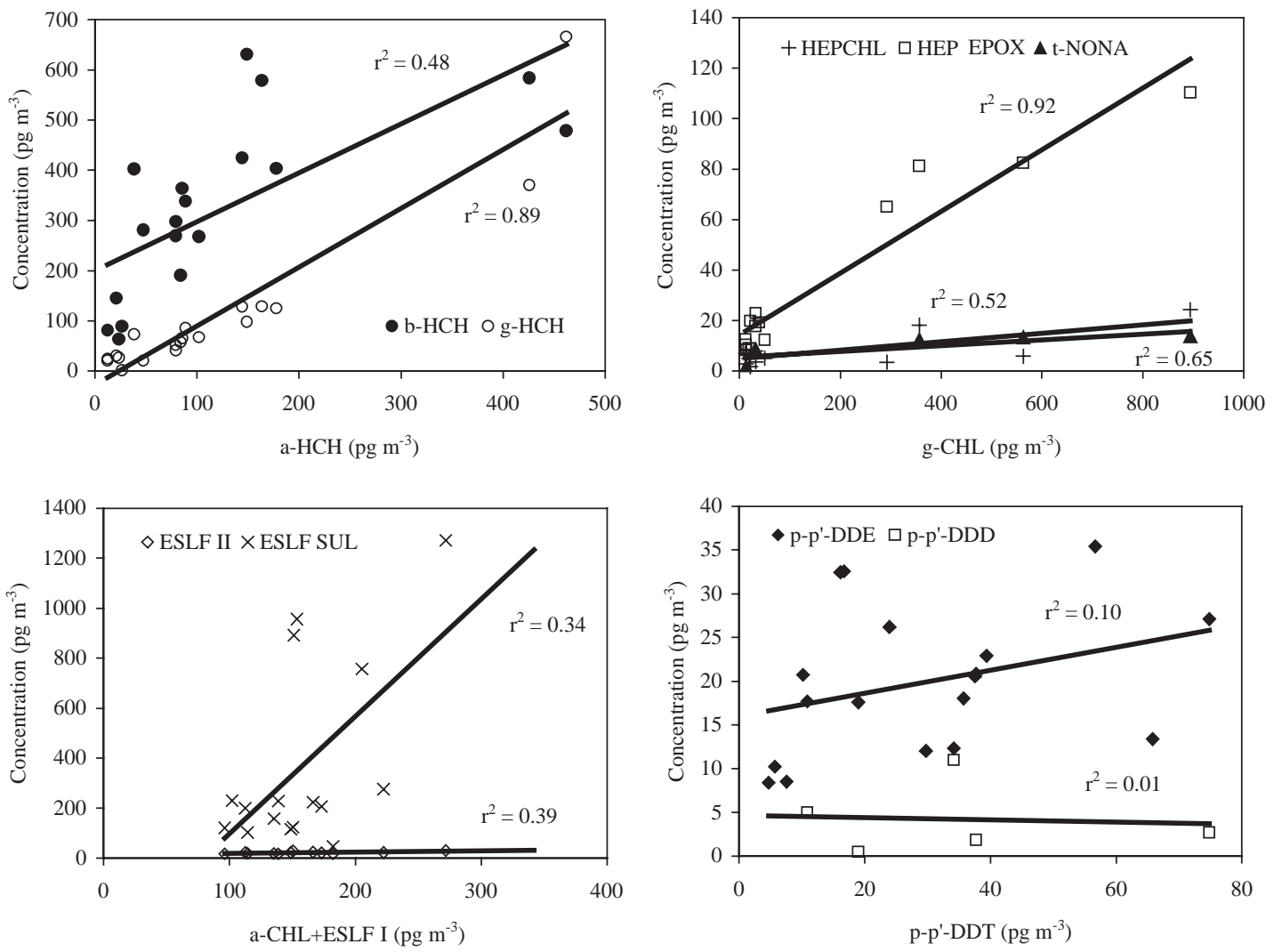

Fig. 1. Correlations between OCPs.

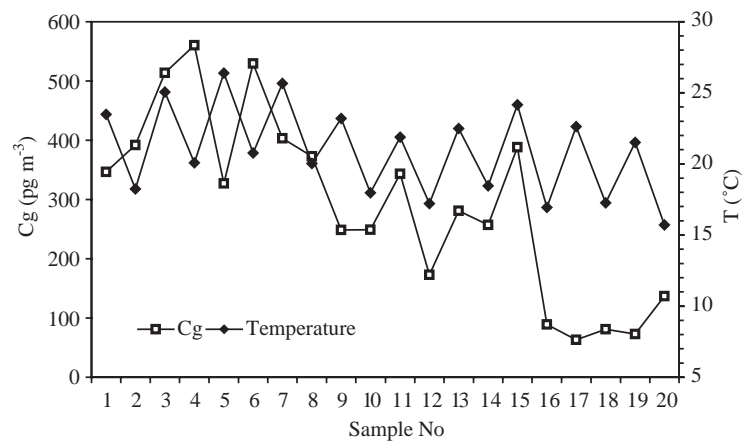

Fig. 2. Diurnal variation of $\beta-\mathrm{HCH}$ and temperature.

reciprocal mean temperature for each sampling period. The mean temperature was obtained by averaging the temperatures measured in $1 \mathrm{~min}$ intervals over the each sampling period and ranged from $15.7^{\circ} \mathrm{C}$ to $26.4^{\circ} \mathrm{C}$ during the sampling program.

For the OCPs included in this study, the temperature dependence of gas-phase concentrations was statistically significant only for $\beta$ - $\mathrm{HCH}$ and endosulfan sulfate $(p<0.1)$ and was not statistically significant for other compounds. The temperature accounted for 0 (hepta- chlor epoxide, endrin aldehyde, $\mathrm{p}, \mathrm{p}^{\prime}$-dichlorodiphenyltrichloroethane (p-p'-DDT)) to $21 \%$ (endosulfan sulfate) of the variability in gas-phase concentrations.

Inferences can be done using the slope $(m)$ and coefficient of determination $\left(r^{2}\right)$ with regard to the importance of temperature in controlling the gas-phase ambient concentrations of SOCs and the relative importance of other factors (Lee et al., 2000). Generally steep slopes and high $r^{2}$ values indicate that temperature-controlled air-surface cycling and short-term transport influences the ambient gas-phase concentrations (Hoff et al., 1998; Wania et al., 1998). Relatively shallow slopes and low $r^{2}$ values suggest that other factors (i.e., advection, ongoing sources, wet and dry deposition, atmospheric reactions) and long-range transport influence concentrations (Lee et al., 2000). The relatively shallow slopes and low $r^{2}$ values for some OCPs observed in this study suggest that long-range transport influenced their gas-phase concentrations (Hoff et al., 1998; Wania et al., 1998) or temperature dependency was affected by confounding factors (advection and proximity of the sources).

Temperature could not explain the majority of the variation in atmospheric gas-phase OCP concentrations. Wind speed and direction could be other parameters 
affecting the gas-phase OCP concentrations. Examination of the meteorological parameters suggested that advection may be an important factor. During the sampling program the variation of temperature and wind speed was similar. Nighttime periods with lower temperatures corresponded to lower wind speeds while daytime periods with higher temperatures corresponded to more advective (higher wind speeds) conditions (Table 1, Fig. 3). Therefore, advection probably masked the temperature-dependent diurnal cycling of most OCPs.

The effect of wind speed and direction on gas-phase atmospheric concentrations of individual OCPs was investigated adding these parameters into Eq. (2) and using multiple linear regression analysis (Hillery et al., 1997):

$\ln P=m_{1}(1 / T)+m_{2} U+m_{3} \cos \mathrm{WD}+b$,

where $U$ is the wind speed $\left(\mathrm{m} \mathrm{s}^{-1}\right)$, WD is the predominant wind direction during the sampling period (deg), $m_{1}, m_{2}, m_{3}$, and $b$ are the regression parameters. The results of multiple linear regression analysis are presented in Table 4. Temperature, wind speed, and wind direction together explained the $2 \%$ (aldrin) to $72 \%$ (endosulfan II) of the variability in gas-phase concentrations. The correlation was statistically significant for 10 OCPs $(p<0.05$ or $p<0.1)$. For all OCPs except chlorpyrifos $m_{1}$ was negative indicating that their concentrations increased with temperature. $m_{1}$ was statistically significant for $\alpha, \beta, \gamma-\mathrm{HCHs}$, heptachlor epoxide, $\gamma$-chlordane, endosulfan sulfate, and methoxychlor. Their slopes were relatively steep and ranged between -9703 and $-21,411$ suggesting that their ambient concentrations were influenced by short-range or regional transport. The relatively shallow slopes obtained for other OCPs suggest that their concentrations affected by long-range transport. However, the positive value obtained for chlorpyrifos and shallow slopes for endosulfan I and II can be attributed to the influence of their ongoing sources. For most of the

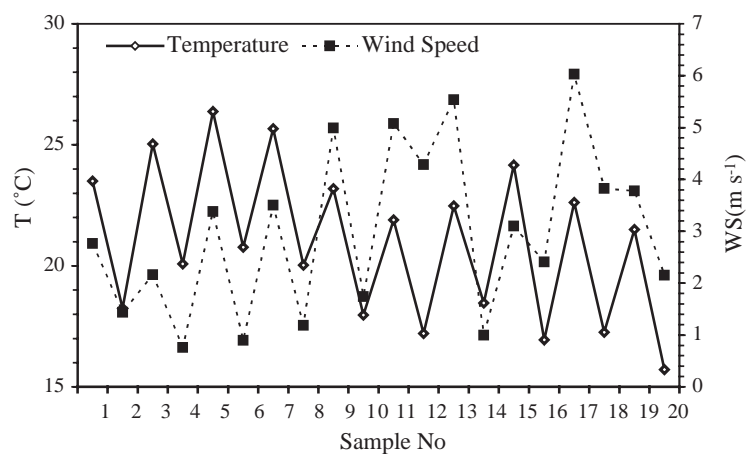

Fig. 3. Diurnal variation of temperature and wind speed.
Table 4

Summary of regression parameters for Eq. (3)

\begin{tabular}{lcccll}
\hline & $m_{1}$ & $m_{2}$ & \multicolumn{1}{l}{$m_{3}$} & $r^{2}$ & $n$ \\
\hline$\alpha$-HCH & $-10,630^{\mathrm{b}}$ & $-0.29^{\mathrm{a}}$ & $0.63^{\mathrm{b}}$ & $0.52^{\mathrm{a}}$ & 19 \\
$\beta$-HCH & $-9703^{\mathrm{a}}$ & $-0.22^{\mathrm{a}}$ & $0.45^{\mathrm{a}}$ & $0.70^{\mathrm{a}}$ & 20 \\
$\gamma$-HCH & $-13,697^{\mathrm{a}}$ & $-0.40^{\mathrm{a}}$ & -0.06 & $0.47^{\mathrm{a}}$ & 19 \\
HEPCHL & -4184 & -0.15 & 0.03 & 0.15 & 19 \\
CHLPYR & 1584 & $-0.26^{\mathrm{b}}$ & 0.34 & $0.34^{\mathrm{b}}$ & 20 \\
ALD & -1082 & 0.01 & -0.02 & 0.02 & 12 \\
HEP EPOX & $-13,190^{\mathrm{b}}$ & $-0.45^{\mathrm{a}}$ & $-1.04^{\mathrm{a}}$ & $0.46^{\mathrm{b}}$ & 14 \\
$\gamma$-CHL & $-19,829^{\mathrm{a}}$ & $-0.46^{\mathrm{a}}$ & $-2.23^{\mathrm{a}}$ & $0.65^{\mathrm{a}}$ & 15 \\
$\alpha$-CHL+ESLF I & -2658 & -0.07 & 0.00 & 0.16 & 19 \\
p-p'-DDE & -324 & 0.01 & 0.34 & 0.17 & 20 \\
ESLF II & -4417 & -0.06 & $0.35^{\mathrm{a}}$ & $0.72^{\mathrm{a}}$ & 12 \\
END AL & -5293 & $-0.21^{\mathrm{a}}$ & $-0.59^{\mathrm{a}}$ & $0.42^{\mathrm{b}}$ & 17 \\
ESLF SUL & $-21,411^{\mathrm{a}}$ & $-0.33^{\mathrm{a}}$ & 0.45 & $0.60^{\mathrm{a}}$ & 16 \\
p-p'-DDT & -549 & -0.10 & 0.02 & 0.06 & 18 \\
MEOCL & $-12,839^{\mathrm{a}}$ & $-0.30^{\mathrm{a}}$ & -0.31 & $0.31^{\mathrm{b}}$ & 20 \\
\hline
\end{tabular}

${ }^{\mathrm{a}} p<0.05$.

${ }^{\mathrm{b}} p<0.10$.

OCPs $m_{2}$ had also negative values and they were statistically significant for nine OCPs. This indicated that their gas-phase concentrations decreased as the wind speed increased and supported the hypothesis that advection masked the temperature-dependent diurnal cycling of most OCPs. The regression parameter related to wind direction $\left(m_{3}\right)$ varied between negative and positive values and it was statistically significant for six OCPs (Table 4). Negative values for $m_{3}$ indicate that relatively higher gas-phase concentrations were observed when the wind was from southerly directions while positive values point northerly directions for high concentrations. Based on statistically significant $m_{3}$ values, north of the sampling site may be an important source sector for $\alpha, \beta$-HCHs and endosulfan II while south may be an important source sector for heptachlor epoxide, $\gamma$-chlordane and endrin aldehyde. The lack of correlation for heptachlor, aldrin, p-p'-DDE, and p-p'DDT with temperature, wind speed and direction suggests that their gas-phase concentrations were affected by long-range transport.

\subsection{Gas/particle partitioning}

Partitioning of SOCs between the gas and particulate phases is parameterized using the gas/particle partition coefficient, $K_{\mathrm{p}}\left(\mathrm{m}^{3} \mu \mathrm{g}^{-1}\right)$ (Harner and Bidleman, 1998):

$K_{\mathrm{p}}=\left(C_{\mathrm{p}} / C_{\mathrm{TSP}}\right) / C_{\mathrm{g}}$,

where $C_{\mathrm{p}}$ and $C_{\mathrm{g}}$ are the $\mathrm{SOC}$ concentrations in the particulate and gas phases, respectively $\left(\mathrm{pg} \mathrm{m}^{-3}\right)$, and $C_{\text {TSP }}$ is the concentration of total suspended particles in the air $\left(\mu \mathrm{g} \mathrm{m}^{-3}\right)$. 
The octanol-air partitioning coefficient $\left(K_{\mathrm{OA}}\right)$ can be used to predict $K_{\mathrm{p}}$ with the assumption of predominant distribution process is absorption (Harner and Bidleman, 1998). The relationship between $K_{\mathrm{p}}$ and $K_{\mathrm{OA}}$ is

$K_{\mathrm{p}}=\frac{f_{\mathrm{OM}} \mathrm{MW}}{\rho_{\mathrm{OCT}} \mathrm{MW}_{\mathrm{OM}} \zeta_{\mathrm{OM}} 10^{12}} K_{\mathrm{OA}}$,

where $f_{\mathrm{OM}}$ is the fraction of OM phase on TSP, MW $\mathrm{OCT}$ and $\mathrm{MW}_{\mathrm{OM}}$ are the mean molecular weights of octanol and the OM phase $\left(\mathrm{g} \mathrm{mol}^{-1}\right)$, respectively, $\rho_{\mathrm{OCT}}$ is the density of octanol $\left(0.820 \mathrm{~kg} \mathrm{~L}^{-1}\right)$, $\zeta_{\text {OCT }}$ is the activity coefficient of the absorbing compound in octanol, $\zeta_{\mathrm{OM}}$ is the activity coefficient of the compound in the OM phase. With the assumptions that $\zeta_{\text {OCT }} / \zeta_{\text {OM }}$ and $\mathrm{MW}_{\mathrm{OCT}} / \mathrm{MW}_{\mathrm{OM}}=1$, Eq. (5) can be written as:

$\log K_{\mathrm{p}}=\log K_{\mathrm{OA}}+\log f_{\mathrm{OM}}-11.91$.

The $K_{\mathrm{p}}$ values defined in Eqs. (4) (experimental) and (6) (modeled) were calculated for OCPs that could be detected in both gas and particulate phases and for those experimentally determined $K_{\mathrm{OA}}$ values were available $(\alpha-\mathrm{HCH}, \beta-\mathrm{HCH}, \gamma-\mathrm{HCH}$, chlorpyrifos, endosulfan I, dieldrin, p-p'-DDE, and p-p'-DDT). Measured $f_{\mathrm{OM}}$, $C_{\mathrm{TSP}}, C_{\mathrm{g}}, C_{\mathrm{p}}$ and $K_{\mathrm{OA}}$ values taken from previous studies used in the calculation of $K_{\mathrm{p}}$. The influence of temperature $(T, K)$ on $K_{\mathrm{OA}}$ is taken into account using the following equation with the regression parameters ( $A$ and $B$ ) given by Shoeib and Harner (2002):

$\log K_{\mathrm{OA}}=A+B / T$.

The parameters $A$ and $B$ were not available for chlorpyrifos. Therefore, for this compound the $K_{\mathrm{OA}}$ value was obtained as the ratio of octanol/water partition coefficient $\left(K_{\mathrm{OW}}\right)$ to dimensionless Henry's law constant $\left(H^{\prime}\right)$ (McConnell et al., 1997). $H^{\prime}$ values as a function of temperature were calculated using the regression parameters given by McConnell et al. (1997).

Plots of $\log K_{\mathrm{p}}$ vs. $\log K_{\mathrm{OA}}$ have been used in field and laboratory studies to evaluate the gas-particle partitioning of SOCs in urban and rural particulate matter (Shoeib and Harner, 2002; Falconer and Harner, 2000). A good correlation between $\log K_{\mathrm{p}}$ and $\log K_{\mathrm{OA}}$ and a slope near 1 indicates that octanol is a good surrogate for the partitioning of SOCs into aerosol OM (Falconer and Harner, 2000). Even though strong correlations were observed between $\log K_{\mathrm{p}}$ and $\log K_{\mathrm{OA}}$, some of the previously reported slope values were significantly different than 1. Slope values of $0.99,0.74$, and 0.65 for OCPs, PCBs, and polychlorinated naphthalenes, respectively, were reported previously (Shoeib and Harner, 2002; Falconer and Harner, 2000; Harner and Bidleman, 1998). Recently, Goss and Schwarzenbach (1998) questioned the necessity of a slope of 1 for equilibrium partitioning when $\log K_{\mathrm{p}}$ is plotted vs. $\log K_{\mathrm{OA}}$. Based on the theoretical considerations and experimental data from the literature, they concluded that the slope might deviate significantly from 1 for equilibrium partitioning. Deviations from a unity slope further indicate that atmospheric particles have sorbing properties different from that of octanol. Despite that these differences, $\log K_{\mathrm{OA}}$ works as a useful predictor for a given class of compounds (e.g., PCBs) as indicated by the good linearity of the regression lines (Goss and Schwarzenbach, 1998).

Fig. 4 is a plot of experimental $\log K_{\mathrm{p}}$ values vs. $\log K_{\mathrm{OA}}$ values. For the plot containing all data, the correlation between $\log K_{\mathrm{p}}$ and $\log K_{\mathrm{OA}}$ was statistically significant $(p<0.01)$. However, the slope of the regression line $(0.46)$ was $<1$. Slope of the regression line may be variable for each sampling event. Therefore, focusing on sorption to particles collected over a single sampling period can reduce fluctuations in atmospheric conditions and particle characteristics. For 10 sampling periods having six or more experimentally determined $K_{\mathrm{p}}$ values, slope of the regression line varied between 0.26 and 0.82 $\left(r^{2}=0.49-0.91\right)$. Plots for selected sampling events are presented in Fig. 4. The variation of slope values suggests that atmospheric particles for different samples have different sorbing properties. Good correlation between $\log K_{\mathrm{p}}$ and $\log K_{\mathrm{OA}}$ suggests that $K_{\mathrm{OA}}$ is a useful predictor for the partitioning of OCPs into aerosol OM.

Fig. 5 compares the experimentally determined and predicted $\log K_{\mathrm{p}}$ values using Eq. (6). The correlation between experimental and modeled $\log K_{\mathrm{p}}$ values was statistically significant $(p<0.01)$ and the slope of the regression line (0.94) was close to 1 indicating that the overall agreement between experimental and predicted values was very good.

Fig. 6 shows the experimental particulate percentages and those predicted by the absorption model. Predicted particulate percentages were calculated using the fraction $(\phi)$ of the compound in the particle phase (Harner and Bidleman, 1998):

$\phi=\left(K_{\mathrm{p}} C_{\mathrm{TSP}}\right) /\left(1+K_{\mathrm{p}} C_{\mathrm{TSP}}\right)$,

where $K_{\mathrm{p}}\left(\mathrm{m}^{3} \mu \mathrm{g}^{-1}\right)$ is the gas/particle partition coefficient and $C_{\text {TSP }}$ is the concentration of total suspended particles in the air $\left(\mu \mathrm{g} \mathrm{m}^{-3}\right)$. Prediction of absorption model was excellent for $\beta-\mathrm{HCH}$, endosulfan I, and $\mathrm{p}-\mathrm{p}^{\prime}$ DDT. However, the model underpredicted the particulate percentages for $\alpha, \gamma-\mathrm{HCHs}$, chlorpyrifos, and dieldrin, and overpredicted the particulate percentage for $\mathrm{p}$ - $\mathrm{p}^{\prime}$-DDE. The absorption model has been generally used assuming that the atmospheric particles contain $10-20 \%$ OM $\left(f_{\mathrm{OM}}=0.1-0.2\right)$ (Shoeib and Harner, 2002; Falconer and Harner, 2000; Harner and Bidleman, 1998). Fig. 6 also shows the predicted particulate 

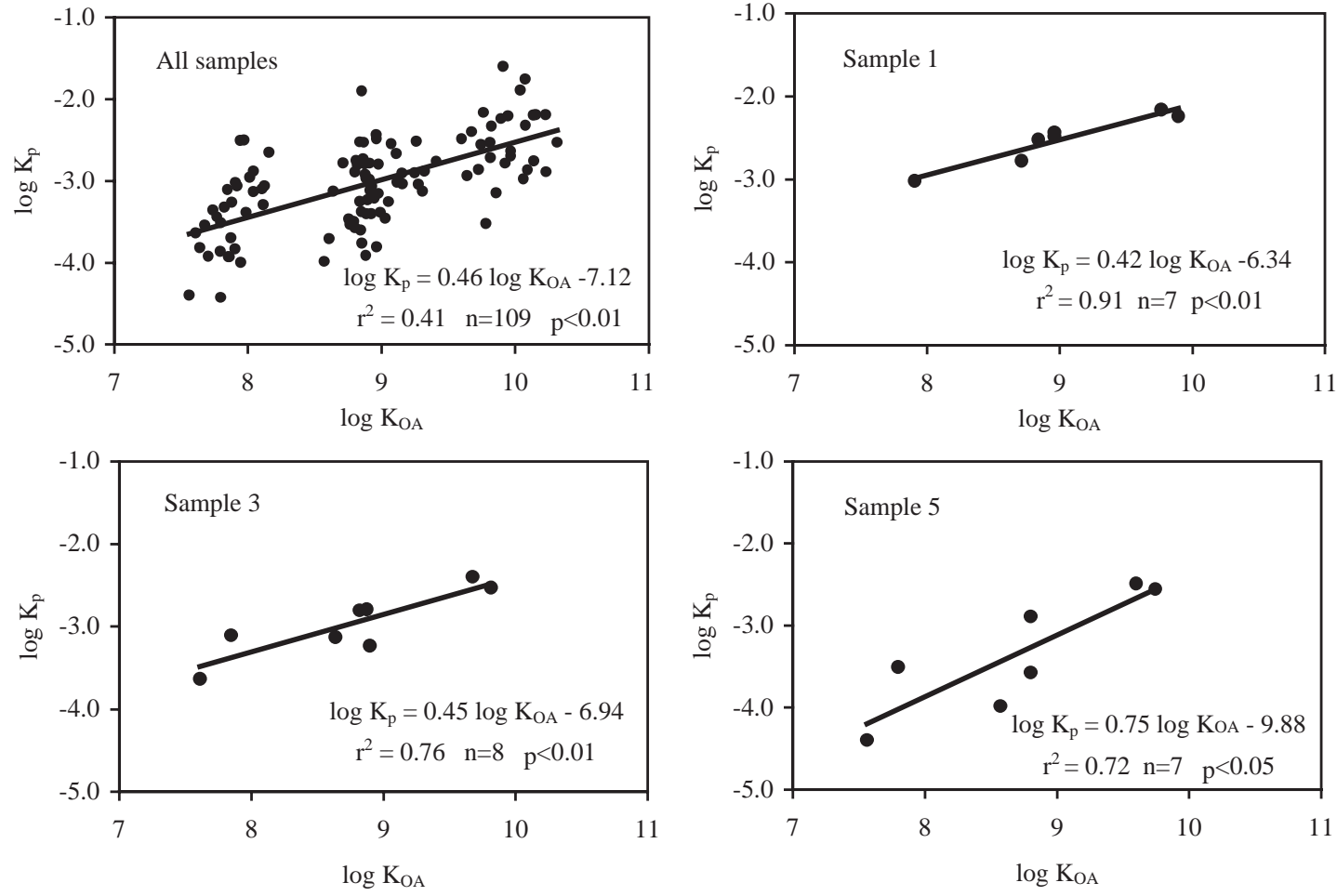

Fig. 4. Plot of $\log K_{\mathrm{p}}$ vs. octanol-air partition coefficients $\left(\log K_{\mathrm{OA}}\right)$.

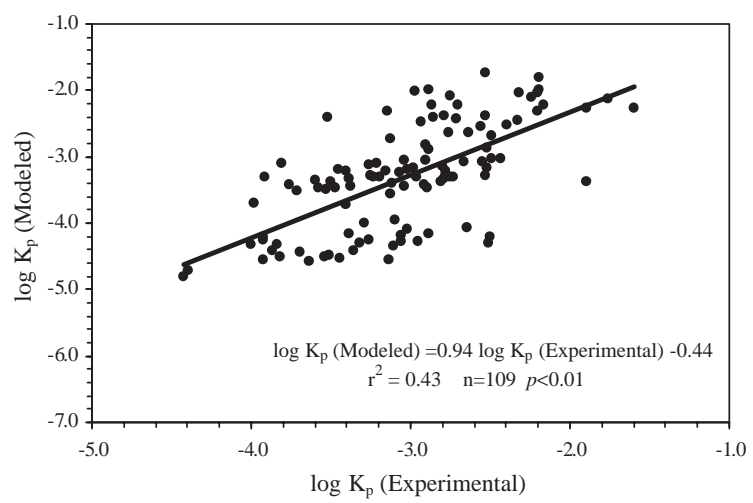

Fig. 5. Comparison of experimental and estimated $\log K_{\mathrm{p}}$ values.

percentages assuming $10 \%$ and $20 \%$ OM. When these assumptions were used, the model substantially underpredicted the experimental particulate percentages indicating the importance of using measured $f_{\mathrm{OM}}$ values. The measured average $f_{\mathrm{OM}}$ values $(0.53)$ in this study were higher than typically expected. These high $f_{\mathrm{OM}}$ values can be attributed to the high pollen content of the air during the sampling period that was obvious from the yellow deposited material on the sampling platform and the filters.

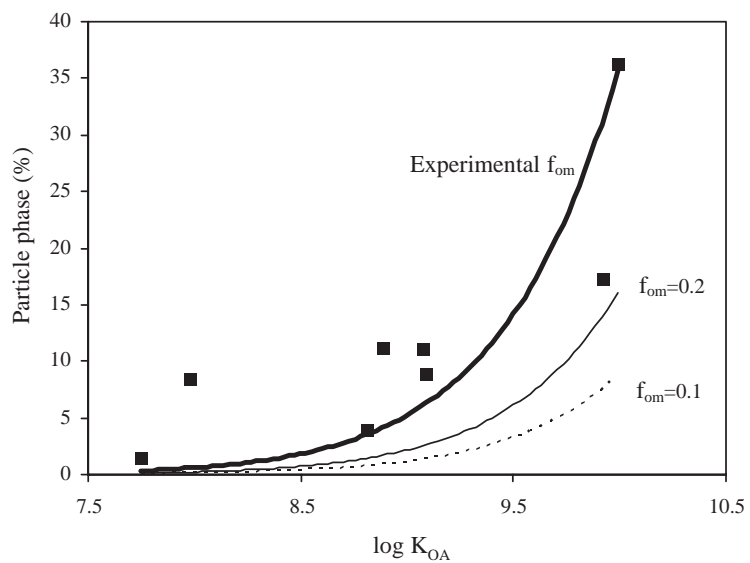

Fig. 6. Comparison of experimental (filled squares) and modeled (solid and dashed lines) particulate-phase percentages.

\section{Acknowledgements}

This study was supported in part by The Scientific and Technical Research Council of Turkey (TUBITAK) (Project No. ICTAG-C033) and the scientific research fund of the Izmir Institute of Technology (Project No. IYTE-20). Support by the Dokuz Eylul University, Testo Inc., Istanbul, Turkey, Remzi Seyfioglu and 
Abdurrahman Bayram of Dokuz Eylul University, Izmir, Turkey is also greatly appreciated.

\section{References}

Ayas, Z., Barlas, N., Kolankaya, D., 1997. Determinations of organochlorine pesticide in various environments and organisms in Göksu Delta, Turkey. Aquatic Toxicology 39, 171-181.

Cortes, D.R., Basu, I., Sweet, C.W., Brice, K.A., Hoff, R.M., Hites, R.A., 1998. Temporal trends in gas-phase concentrations of chlorinated pesticides measured at the shores of Great Lakes. Environmental Science and Technology 32, 1920-1927.

Currado, G.M., Harrad, S., 2000. Factors influencing atmospheric concentrations of polychlorinated biphenyls in Birmingham, UK. Environmental Science and Technology 34, 78-82.

Falconer, R.L., Harner, T., 2000. Comparison of the octanolair partition coefficient and liquid phase vapor pressure as descriptors for particle/gas partitioning using laboratory and field data for PCBs and PCNs. Atmospheric Environment 34, 4043-4046.

Goss, K., Schwarzenbach, R.P., 1998. Gas/solid and gas/liquid partitioning of organic compounds: critical evaluation of the interpretation of equilibrium constants. Environmental Science and Technology 32, 2025-2032.

Halsall, C.J., Bailey, R., Stern, G.A., Barrie, L.A., Fellin, P., Muir, D.C.G., Rosenberg, B., Rovinsky, F.Y., Kononov, E.Y., Pastukhov, B., 1998. Multi-year observations of organohalogen pesticides in the Arctic atmosphere. Environmental Pollution 102, 51-62.

Harner, T., Bidleman, T.F., 1998. Octanol-air partition coefficient for describing particle/gas partitioning of aromatic compounds in urban air. Environmental Science and Technology 32, 1494-1502.

Hillery, B.R., Basu, I., Sweet, C.W., Hites, R.A., 1997. Temporal and spatial trends in a long-term study of gasphase PCB concentrations near the Great Lakes. Environmental Science and Technology 31, 1811-1816.

Hoff, R.M., Brice, K.A., Halsall, C.J., 1998. Nonlinearity in the slopes of Clausius-Clapeyron plots for SVOCs. Environmental Science and Technology 32, 1793-1798.

Honrath, R.E., Sweet, C.W., Plouff, C.J., 1997. Surface exchange and transport processes governing atmospheric PCB levels over the Lake Superior. Environmental Science and Technology 31, 842-852.

Jaward, F.M., Farrar, N.J., Harner, T., Seweetman, A.J., Jones, K.C., 2004. Passive air sampling of PCBs, PBDEs and organochlorine pesticides across Europe. Environmental Science and Technology 38, 34-41.

Lee, R.G.M., Jones, K.C., 1999. The influence of meteorology and air masses on daily atmospheric PCB and PAH concentrations at a UK location. Environmental Science and Technology 33, 705-712.
Lee, R.G.M., Hung, H., Mackay, D., Jones, K.C., 1998. Measurement and modeling of the diurnal cycling of atmospheric PCBs and PAHs. Environmental Science and Technology 32, 2172-2179.

Lee, R.G.M., Burnett, V., Harner, T., Jones, K.C., 2000. Short term temperature dependent air-surface exchange and atmospheric concentrations of polychlorinated naphthalenes and organochlorine pesticides. Environmental Science and Technology 34, 393-398.

Louie, P.K.K., Sin, D.W., 2003. A preliminary investigation of persistent organic pollutants in ambient air in Hong Kong. Chemosphere 52, 1397-1403.

McConnell, L.L., Nelson, E., Rice, C.P., Baker, J.E., Johnson, W.E., Harman, J.E., Bialek, K., 1997. Chlorpyrifos in the air and surface water of Chesapeake Bay: predictions of atmospheric deposition fluxes. Environmental Science and Technology 31, 1390-1398.

Ministry of Agriculture, 2003. General Directorate of Protection and Control.

Murayama, H., Takase, Y., Mitobe, H., Mukai, H., Ohzeki, T., Shimizu, K., Kitayama, Y., 2003. Seasonal change of persistent organic pollutant concentrations in air at Niigata Area, Japan. Chemosphere 52, 683-694.

Odabasi, M., Vardar, N., Tasdemir, Y., Sofuoglu, A., Holsen, T.M., 1999. Polycyclic aromatic hydrocarbons in Chicago air. The Science of the Total Environment 227, 57-67.

Park, J.-S., Wade, T.L., Sweet, S., 2001. Atmospheric deposition of organochlorine contaminants to Galveston Bay, Texas. Atmospheric Environment 35, 3315-3324.

Shoeib, M., Harner, T., 2002. Using measured octanol-air partition coefficients to explain environmental partitioning of organochlorine pesticides. Environmental Toxicology and Chemistry 21, 984-990.

Simcik, M.F., Basu, I., Sweet, C.W., Hites, R.A., 1999. Temperature dependence and temporal trends of polychlorinated biphenyl congeners in the Great Lakes atmosphere. Environmental Science and Technology 33, 1991-1995.

Sofuoglu, A., Odabasi, M., Tasdemir, Y., Khalili, N.R., Holsen, T.M., 2001. Temperature dependence of gas-phase polycyclic aromatic hydrocarbon and organochlorine pesticide concentrations in Chicago air. Atmospheric Environment 35, 6503-6510.

Turgut, C., 2003. The contamination with organochlorine pesticides and heavy metals in surface water in Küçük Menderes River in Turkey, 2000-2002. Environment International 29, 29-32.

Wania, F., Haugen, J.E., Lei, Y.D., Mackay, D., 1998. Temperature dependence of atmospheric concentrations of semivolatile organic compounds. Environmental Science and Technology 32, 1013-1021.

Yeo, H.-G., Choi, M., Chun, M.-Y., Sunwoo, Y., 2003. Concentration distribution of polychlorinated biphenyls and organochlorine pesticides and their relationship with temperature in rural air of Korea. Atmospheric Environment 37, 3831-3839. 